\title{
KEBIJAKAN REDAKSIONAL RADAR SULBAR TENTANG BERITA PENDIDIKAN DALAM MENDUKUNG MAJENE SEBAGAI PUSAT PENDIDIKAN DI PROVINSI SULBAR
}

\author{
Editorial Policy of Radar Sulbar Releated to Education Report in Supporting \\ Majene Regency as the Center of Education in West Sulawesi Province
}

\author{
${ }^{1}$ Anugrawati MS, ${ }^{2}$ Hasrullah, ${ }^{3}$ M.Iqbal Sultan
}

\begin{abstract}
${ }^{1}$ Jurusan Ilmu Komunikasi, Fakultas Ilmu Sosial dan Ilmu Politik, Universitas Hasanuddin, Makassar (nughcancerseis@yahoo.com)

${ }^{2}$ Jurusan Ilmu Komunikasi, Fakultas Ilmu Sosial dan Ilmu Politik, Universitas Hasanuddin, Makassar (has_ullah@yahoo.com)

${ }^{3}$ Jurusan Ilmu Politik, Fakultas Ilmu Sosial dan Ilmu Politik, Universitas Hasanuddin, Makassar (miqsul@yahoo.com)
\end{abstract}

\begin{abstract}
ABSTRAK
Penelitian ini bertujuan mengetahui: (1) porsi pemberitaan seputar pendidikan di Majene lebih sedikit dibanding isu lain. (2) kebijakan redaksional Radar Sulbar dalam mendukung Majene sebagai pusat pendidikan di Sulbar. (3) faktor - faktor yang mempengaruhi kebijakan redaksional Radar Sulbar tentang berita pendidikan. (4) kelemahan dan kelebihan kebijakan redaksional Radar Sulbar dalam mendukung Majene sebagai pusat pendidikan di Sulbar. Penelitian ini menggunakan metode kualitatif deskriptif dengan menggabungkan analisis gatekeeping model Pamela J Shomaker dan Stephen D Reese. Penelitian ini dilakukan di Radar Sulbar Kabupaten Mamuju dan Majene. Jenis sumber data yang digunakan adalah data primer dan data sekunder. Data primer adalah hasil wawancara para redaktur dan berita - berita di Radar Sulbar edisi Januari - Maret 2016. Data sekunder berupa buku, tesis, skripsi, jurnal dan internet. Informan sebanyak delapan orang. Data analisis menggunakan beberapa teori. Hasil penelitian menunjukkan bahwa (1) Pemberitaan pendidikan Majene secara kuantitas di bawah dibading isu lain dipengaruhi kurangnya wartawan lapangan dan juga tidak adanya penekanan memunculkan berita pendidikan setiap hari. (2) Kebijakan Redaksional Radar Subar mendukung Majene sebagai pusat pendidikan dengan memberi penguatan kepada beberapa isu pendidikan saja. (3) Faktor faktor yang dominan mempengaruhi kebijakan redaksional Radar Sulbar terkait berita pendidikan diantaranya ideologi dan organisasi. (4) Kelebihan kebijakan redaksional Radar Sulbar dalam mendukung Majene sebagai pusat pendidikan di Sulbar terlihat dari rubrik pendidikan Go madrasah dan konsistensi pemberitaan yang meski memiliki kerjasama iklan di lintas sektoral tidak mengurangi fungsi kontrolnya. Kelemahan : Rubrik Health and Education masih di dominasi berita nasional dan sebagian kecil berita lokal di Sulbar.
\end{abstract}

Kata kunci : Kebijakan Redaksional, berita pendidikan, Radar Sulbar, Gatekeeper.

\begin{abstract}
The role of the mass media in this regard not only present Sulbar Radar mengibur information but also provide their support in terms of education. This research aims to find out: (1) the portion of education report publication in Majene is less than another issue, (2) Editorial policy of Radar Sulbar in supporting Majene Regency as the Center of Education, (3) several factors that influence editorial policy of Radar Sulbar related to education report, and (4) the weaknesses and strengthens of redaction policy of Radar Sulbar in supporting Majene as the center of Education in West Sulawesi Province. The method of this research was qualitative descriptive design by combining gatekeeping analysis model by Pamela J. Shoemaker and Stephen D. Reese. The research conducted in Radar Sulbar office in Mamuju and Majene Regency. In collecting the data, the researcher used primary and secondary data. The primary data obtained by interviewing editors and collecting Radar Sulbar news report from January to March 2016. The secondary data obtained by data from books,
\end{abstract}


thesis, minithesis, journals and internet. The result of this research showed that: (1) In quantity, the news report about education in Majene is lower than other issues which influenced by the lack of field reporters and the emphasizing to publish education report every day, (2) Editorial policy of Radar Sulbar in supporting Majene as the center of education focused only in several issues of education, (3) The dominant factors that influence the redaction policy of Radar Sulbar related to education news were ideology and organization and (4) Editorial policy of Radar Sulbar indeed supported Majene Regency as the center of education through an education rubric Go Madrasah and the consistency of publishing with full control although the advertisement cooperation by sector passage took part with the daily. Weakness: Health and Education rubric was dominated by national news and only a small part taken by local news report in West Sulawesi Province.

Keywords: Editorial Policy, Education News Report, Radar Sulbar, Gatekeeper.

\section{PENDAHULUAN}

Majene sebagai ikon pendidikan di provinsi Sulawesi Barat (Sulbar) melalui proses tarik ulur politik yang panjang. Beragam stigma dan sikap pesimisme muncul terkait kepantasan Majene sebagai pusat pendidikan di Provinsi yang saat itu merupakan daerah otonomi baru (DOB). Pemerintah Kabupaten (Pemkab) Majene dengan segala keterbatasan anggaran terus berbenah. Setiap tahunnya Pemkab Majene selalu mengalokasikan anggaran paling tinggi di sektor pendidikan dibanding satuan kerja perangkat daerah (SKPD) lainya. Posisi tersebut diperkuat dengan keberadaan universitas negeri satu-satunya di Sulbar, yakni Universitas Sulawesi Barat (Unsulbar), Universitas Terbuka, Institut Agama Islam Negri (IAIN) yang masih dalam pembangunan dan berpusatnya Lembaga Penjamin Mutu Pendidikan Provinsi Sulbar (LPMP) di wilayah Majene.

Pemkab Majene juga menuangkan dalam bentuk peraturan daerah (Perda) No 2 Tahun 2014 tentang Pengelolaan dan Penyelenggaraan Pendidikan. Pemerintah Provinsi Sulbar tak ketinggalan ikut menguatkan komitmen, dalam Peraturan Daerah Rencana Tata Ruang Wilayah (RTRW) Provinsi Sulbar Tahun 2014-2034. Pasal 4 tentang kebijakan penataan ruang wilayah dengan mengembangkan Pusat-pusat Kegiatan Wilayah (PKW) sebagai pusat pelayanan pendidikan.

Hanya saja untuk mendapat perhatian media massa terutama media pusat yang memiliki akses kuat untuk mempengaruhi opini publik tidak semudah yang diharapkan. Media yang mapan secara financial akan menyeleksi ketat isu atau tema liputan. Maka untuk mengcover kebutuhan informasi yang sepadan dengan kebutuhan khalayak di daerah, media dengan skala lokal memegang peranan tersebut. Dalam hal ini media massa lokal atau surat kabar lokal yang beredar baik skala regional yang lazimnya membangun ciri dan karakteristiknya sendiri atau yang mengembangkan diseminasi kedekatan geografis dan kedekatan psikologis (proximity) untuk menjaring pembacanya Sumadirida (2005). Idealnya media tidak hanya memberikan perhatian pada satu isu tertentu saja. Masyarakat memiliki hak untuk mendapat informasi beragam sesuai dengan prinsip keberagaman berita (diversity), juga prinsip (fairness) berdasarkan pada prinsip keterwakilan secara proposional Morissan dkk (2013).

Radar Sulbar yang merupakan media terbesar dan pertama di Sulawesi Barat tentu akan menjadi rujukan masyarakat dalam menyerap informasi. Sesuai cita-cita pemkab Majene sebagai pusat pendidikan di Sulbar, maka kehadiran Radar Sulbar diharapkan menjadi media proaktif dalam mendukung pemerintah setidaknya dalam menciptakan atmosfer pendidikan melalui informasi atau berita. Dari hasil olah data, peneliti menemukan fakta sepanjang Juli-Desember tahun 2015, total berita Majene untuk tiap rubrik sebanyak 712 berita. Berita di luar pendidikan diantaranya politik, ekonomi, kriminal dan pemerintahan sebanyak 638 berita atau 89,61 \%. Sementara berita pendidikan Majene hanya 74 berita atau 10,39 $\%$. Terlihat porsi pemberitaan pendidikan lokal Majene masih jarang menjadi fokus pemberitaan meskipun telah memiliki dua rubrik. Terkait hal tersebut tiap pilihan berita yang dimunculkan surat kabar masuk dalam ranah kebijakan redaksi yang juga diartikan sebagai proses penentuan sikap yang dimiliki oleh sebuah media massa dalam menanggapi sebuah fenomena yang terjadi pada masyarakat. 
Penelitian ini bertujuan untuk mengetahui dan menganlisis seperti apa kebijakan redaksional Radar Sulbar dalam mendukung Majene sebagai pusat pendidikan di Sulbar dan juga seperti apa kelemahan dan kelebihan kebijakan tersebut.

\section{BAHAN DAN METODE \\ Lokasi dan Rancangan Penelitian}

Lokasi Penelitian bertempat di Kantor Harian Radar Sulbar di kabupaten Mamuju dan Kabupaten Majene Provinsi Sulbar. Objek penelitian ini adalah para gatekeeper atau redaktur di Radar Sulbar yang paling mengetahui alur seleksi berita pendidikan. Selain itu peneliti juga melakukan penghitungan berita pendidikan periode januari - maret 2016. Jumlah informan yang dipilih 8 (delapan) orang, yang masing masing dipilih secara sengaja (purposive sampling) dengan pertimbangan mereka dianggap tahu dan dapat dipercaya untuk menjadi sumber data yang akurat dan mengetahui masalah secara mendalam. Masing - masing terdiri dari Direktur Pelaksana Harian Radar Sulbar, Pimpinan Redaksi Radar Sulbar, Wakil Pimpinan Redaksi Radar Sulbar, Kepala Biro Radar Sulbar Majene, Wartawan Radar Sulbar Biro Majene, Sekertaris Daerah Kab Majene, Kepala Dinas Pendidikan Kab Majene.

\section{Sumber Data}

Peneliti menggunakan sumber data primer dan data sekunder. Data primer merupakan tanya jawab secara langsung dengan para informan di Radar Sulbar termasuk mengumpulkan dokumen berita berita pendidikan periode januari - maret 2016 di Radar Sulbar. Data sekunder adalah data yang menunjang dalam kegiatan penelitian, seperti buku-buku referensi, tesis, skripsi, jurnal, atikel ilmiah di internet.

\section{Teknik Pengumpulan Data}

Teknik pengumpulan data penelitian dilakukan ini berdasarkan kebutuhan analisis dan pengkajian. Pengumpulan data tersebut sudah dilakukan sejak penulis menentukan permasalahan yang sedang dikaji. Pengumpulan data yang penulis lakukan berorientasi dengan menempuh tahap seperti, Penelitian pustaka (library research), dengan mempelajari dan mengkaji literatur yang berhubungan dengan permasalahan, untuk mendukung asumsi sebagai landasan teori permasalahan yang dibahas. Pencarian sumber data pendukung dengan menganalisa berita berita di harian Radar Sulbar edisi Januari Maret 2016.

\section{Teknis Analisis Data}

Teknik analisa data yang akan digunakan peneliti dalam penelitian ini adalah kualitatif deskriptif. Analisis data dalam penelitian berupa reduksi data, sajian data dan verifikasi. Penulis juga menggabungkan dengan Analisis Gatekeeping Model Pamela J Shomaker dan Sthephen D Reese, yang secara detail menganalisa di lima level, yakni individu, rutinitas, organisasi, extra media dan ideologi. Dengan model analisis ini, maka kerangka analisisnya berusaha mendeteksi, menyeleksi, penonjolan atas tiap pengaruh ataupun faktor - faktor yang mempengaruhi kebijakan redaksional Radar Sulbar tentang berita pendidikan dalam mendukung Majene sebagai pusat pendidikan di Sulbar.

\section{HASIL}

\section{Porsi Pemberitaan PendidikanMajene di Radar Sulbar}

Pada bagian latar belakang peneliti telah mencantumkan seperti apa porsi pemberitaan pendidikan khususnya di Majene periode Juli - Desember 2015, yang sekaligus menjadi landasan utama penelitian ini. Untuk melengkapi data tersebut, peneliti kembali melakukan perhitungan pemberitaan pendidikan, namun mencakup seluruh kabupaten di Sulbar. Tujuan nya untuk melihat apakah kecenderungan yang terlihat di biro / kabupaten Majene sama ataukah berbeda dengan lima biro / kabupaten lainya di Sulbar. Penghitungan dilakukan selama tiga bulan (Januari, Februari, Maret) di tahun 2016.

Hasilnya 184 berita pendidikan yang muncul tertinggi di Kabupaten/ biro Polman sebanyak 86 berita atau 46,7 \%, kemudian biro Majene 57 berita atau 31,1 \%, disusul biro Mamuju 36 berita atau 19,60 \%, kemudian biro Mamasa 1,63\% atau hanya tiga berita. Mateng dan Matra sama di posisi terbawah dengan hanya memunculkan masing- masing satu berita atau 0,5\%. Lemahnya porsi berita pendidikan lokal di Majene dipengaruhi beberapa faktor. Diantaranya wartawan yang jumlahnya kurang, perhatian guru untuk di publikasikan media juga masih lemah karna kurangnya komunikasi dengan jurnalist, faktor 
mewabahnya wartawan "bodrex" (wartawan gadungan) yang berkeliaran di sekolah dengan berbagai motif. Diantaranya mencari-cari kesalahan, mengancam pihak sekolah hingga memeras pihak sekolah atau kepala sekolah. Hal tersebut berimbas negatif kepada wartawan resmi, mengingat para guru atau kepala sekolah tidak jarang menghindar bahkan menolak untuk diwawancara atau saat mencari data.

\section{Kebijakan Redaksional Radar Sulbar yang mendukung Pemkab Majene Sebagai Pusat Pendidikan.}

Radar Sulbar dengan jumlah pelanggan terbesar di harapkan menjadi media yang intens mentransformasikan berita informatif juga mengadung nilai kependidikan dalam mendukung Majene sebagai pusat pendidikan di Sulbar. Secara kuantitas, terlihat Radar Sulbar tidak begitu intens menghadirkan berita pendidikan khususnya dalam skala lokal di Majene. Dalam mendukung Majene sebagai pusat pendidikan, tidak dilakukan melalui intensitas pemberitaan setiap hari. Namun dalam beberapa issue tertentu, Radar Sulbar memfokuskan diri sesuai yang disinkronkan dengan strong point Pemerintah, yang salah satunya mengadirkan sarana pendidikan yang merepresentasikan Majene kedepan sebagai "Jogjanya" Sulbar dan juga mendukung Unsulbar menjadi simbol Majene sebagai pusat pendidikan, termsuk mendorong pendirian kampus IAIN dan masih banyak lagi.

\section{Faktor - Faktor yang Mempengaruhi Kebijakan Redaksional Radar Sulbar Tentang Berita Pendidikan. \\ Individu. Berita yang dihimpun} wartawan Radar Sulbar harus melalui pengawasan seorang redaktur, tidak hanya menyeleksi layak atau tidaknya untuk dimuat tapi juga mengubah susunan kata, anggle dengan tujuan membuat berita lebih menarik lagi. Redaktur memang memiliki hak untuk menyeleksi ataupun mengcancel berita dari wartawan. Namun seperti yang penjelasan di atas, sebenarnya proses seleksi isu berasal dari bawah ke atas, dimana setiap isu yang diajukan saat listing berita umumnya berasal dari wartawan, mengingat wartawan daerahlah yang paling mengetahui kondisi di lapangan. Meskipun begitu selalu ada koordinasi dengan redaktur di kantor pusat.
Rutinitas. Di Radar Sulbar selain memahami dan menaati kode etik jurnalistik dan Undang - Undang Pers, media memliki aturan " main " sendiri. Dalam menjalankan tugasnya seorang redaktur memiliki panduan semacam buku saku bersama untuk seluruh group Jawa Pos, di dalamnya memuat aturan baku penulisan yang dinamakan buku "Satu Kata “. Selain itu, ada juga aturan lain yang harus di fahami seluruh personil redaksi ialah masalah deadline, hal tersebut sangat krusial karna tidak hanya menyangkut kedisiplinan para wartawan tapi juga berkaitan arus distribusi berita nantinya.

Organisasi. Radar Sulbar merupakan anak perusahaan dari Fajar Group dan Jawa pos, secara hirarki posisi tertinggi dipegang oleh Komisaris Utama, Direktur Utama dan Direktur Pelaksana. Perusahaan media massa tidak hanya dari divisi redaksi juga ada bagian lain yang mendukung keberlangsungan hidup perusahaan. di Radar Sulbar ada empat divisi diantaranya redaksi, marketing, sirkulasi dan iklan serta Sponshorship. Permasalahan yang kerap terjadi ketika tiap divisi memiliki srategi dan kebijakan yang berbeda sehingga divisi lain merasa terganggu. Redaksi Radar Sulbar sangat tertib untuk masalah tersebut. Solusinya redaksi akan memisahkan antara berita yang sifatnya iklan atau umum. Karna bagaimanapun untuk menjalankan roda perusahan sumber pendapatan terbesar datang dari iklan, kedua sirkulasi. Dalam hal ini menurutnya redaksi harus pintar memilah bagaimana ruang redaksi tidak terciderai.

Ekstra Media. Organisasi media tidak lepas dari pengaruh-pengaruh yang berasal dari luar organisasi. Pengaruh-pengaruh dari media itu bisa berasal dari sumber berita, pengiklan, kontrol dari pemerintah, pangsa pasar dan teknologi. Pengiklan dan Audience. Salah satu bentuk toleransi yang masuk ke ruang redaksi adalah pertimbangan iklan dan audiens hal ini berkaitan dengan keberlangsungan hidup perusahaan. Karena itulah berita yang mereka produksi harus disesuaikan dengan kepentingan lain yang berasal dari luar media.

Ideologi. Sebagai anak perusahaan dari Fajar Group dan Jawa Pos, tentu memiliki kesamaan ideologi, yakni berdasarkan pancasila dan fungsi mencerdaskan bangsa. Sebagai koran lokal, Radar Sulbar dalam misinya mendorong percepatan pembangunan Sulbar termasuk percepatan perda RTRW 
provinsi Sulbar, berita yang di munculkan tidak jauh dari berita pemerintahan khususnya kebijakan pemerintah. Salah satu kebijakan Radar Sulbar, dengan berusaha mengurangi porsi berita yang berefek negatif misalnya demostrasi. Jika beberapa media nasional sangat kental faham ideologinya, maka Radar Sulbar fokus pada kepentingan daerah sesuai cita cita pembentukan Sulbar. Meski demikian aturan baku semisal UU Pers, kode etik Jurnalistik juga menjadi ideologi dalam melaksanakan fungsi jurnalistiknya.

\section{Kelebihan dan kelemahan kebijakan redaksional Radar Sulbar dalam mendukung pemerintah Kabupaten Majene sebagai pusat pendidikan di Sulbar.}

Sebagai media yang populer di Sulbar tentu memiliki andil besar, baik dalam perannya mendukung setiap kebijakan pemerintah atau bahkan mengkritisi kebijakan yang di anggap bersebrangan dengan kepentingan rakyat. Untuk melihat kecenderungan tersebut, tentu saja dapat di tilik dari seberapa besar porsi perhatian media terkait isu kebijakan yang berlaku di tiap wilayah.

Kelebihan kebijakan redaksional Radar Sulbar dalam mendukung Majene sebagai pusat pendidikan, salah satunya rubrik Go Madrasah yang baru setahun di hadirkan setiap weekend (sabtu). Alasan di hadirkanya rubrik tersebut untuk merangsang minat baca masyarakat, dengan menghadirkan prestasi yang ada di madrasah mulai tingkat Tsanawiah, Ibtidaiyah hingga Aliah. Selain itu masih ada stigma negatif yang berkembang di masyarakat, terkait sekolah berbasis religi yang dianggap sebelah mata. Berbeda dengan rubrik lainya yang menempatkan iklan berbayar semisal banner iklan pemerintah daerah dan release berita, pada rubrik Go Madrasah seluruh artikelnya merupakan prodak jurnalistik yang bebas biaya. Para guru di madrasah juga diperkenankan untuk menulis opini maupun artikel di rubrik tersebut. Kelebihan lain, dari segi pemberitaan Radar Sulbar berupaya menjaga marwah keredaksian. Hampir terlihat di setiap halaman kecuali halaman sambungan dan halaman opini di dominasi iklan, fakta tersebut menunjukan pengaruh di sektor extra media yang bisa saja merenggut kewibawaan redaksi dengan berbagai macam intervensi. Menurut Radar Sulbar ada hal terpisah, tiap perjanjian kerjasama iklan tidak ada klausul yang boleh menggangu kenyamanan redaksi dalam memproduksi berita.

Kelemahan. Konsep harian umum menjadi flatform pemberitaan Radar Sulbar, yang berarti hampir seluruh segmen diupayakan termuat dalam sekali terbit. Diperoleh data bahwa isu pendidikan baik skala Sulbar dan terkhusus Majene secara kuantitas masih dibawah dengan isu di luar pendidikan mengingat berita pendidikan tidak mesti hadir setiap harinya karna terkait situasi yang berkembang saat itu. Radar Sulbar memiliki rubrik pendidikan reguler yakni rubrik Health and Education (HE). Muatan berita yang dimunculkan tidak hanya berita pendidikan saja tapi juga informasi kesehatan. Untuk komposisi berita dalam halaman tersebut, umumnya terdapat dua - tiga berita. Satu berita kesehatan dan dua berita pendidikan. Kelemahan yang penulis temukan bahwa berita dalam rubrik tersebut lebih banyak mengulas berita pendidikan nasional yang di sadur dari JPNN dan hanya sebagai kecil berita lokal di Sulbar.

\section{PEMBAHASAN}

Penelitian ini memperlihatkan sedikitnya porsi berita pendidikan lokal Majene, karna tidak adanya penonjolan berita pendidikan dan juga tidak ada penugasan di sektor pendidikan bagi setiap wartawan Radar Sulbar meski telah memiliki rubrik pendidikan. Hal tersebut dipengaruhi konsep surat kabar umum yang sifatnya tidak bersandar pada genre tertentu. Namun ditegaskan, bahwa ada isu pendidikan tertentu yang bisa menjadi fokus redaksi, jika hal tersebut dianggap penting dan membutuhkan dorongan media massa. Keterangan tersebut menunjukan Radar Sulbar melakukan penentuan agenda (agenda setting) menyangkut isu yang harus dimunculkan. Asumsi awal penentuan agenda karena konsentrasi media massa hanya beberapa masalah masyarakat untuk ditanyangkan/ diterbitkan sebagai isu-isu yang lebih penting dari pada isu-isu lain Tamburaka (2012).

Faktor - faktor yang mempengaruhi kebijakan Redaksioanl Radar Sulbar dengan menggunakan analisis gatekeeping model Shomaker dan Vos dalam Madhiyani (2015) sebagai berikut :

Gatekeeping Level Individual Studi pada level individu berfokus pada penggunaan teori-teori berpikir, dimana seorang gatekeeper 
mengevaluasi dan mengartikan pesan teori pengambilan keputusan yang juga berkaitan dengan karakteristik personal individu termasuk latar belakang, nilai, aturan serta pengalaman yang dimiliki Shoemaker \& Vos dalam Mardhiyani (2015). Tiap gatekeeper memulai kegiatan dengan proses berfikir mengenai berita yang layak dan menarik untuk di terbitkan. Setalah mendapatkan kiriman berita dari wartawan tidak akan di loloskan begitu saja. Gatekeeper masih akan teliti menyeleksi tiap bait naskah wartawan, bahkan tidak jarang perubahan narasi hingga penonjolan anggle akan dilakukan. Hal ini lah yang disebut bahwa seorang gatekeeper memiliki news judgment.

Gatekeeping Level Rutinitas Media Deadline, news value, rapat redaksi merupakan rutinitas redaksi di media massa. Setiap awak redaksi telah mengetahui dan faham sehingga dalam aktivitasnya tanpa di ingatkan mereka telah terbiasa mengikuti pola yang menjadi aturan di perusahaan. Sebagai bagian dari kelompok, seorang jurnalis akan bertindak sesuai dengan aturan dan norma yang berlaku di kelompoknya. Norma dan aturan tersebut mengatur seorang jurnalis harus bertindak. Karena itulah, isi media juga dipengaruhi oleh kebiasaan atau aturan yang ditetapkan, Shoemaker dan Reese dalam Tohir (2013). Penjelasan diatas sinkron dengan pertimbangan yang dilakukan Radar Sulbar. Para informan mengatakan Radar Sulbar selalu mempertimbangkan potensi jumlah pembaca.

Gatekeeping Level Organisasi. Level ini berkaitan dengan struktur menajemen organisasi pada sebuah media, kebijakan sebuah media dan tujuan sebuah media. Di berbagai perusahaan media penentu kebijakan termasuk pemberitaan dipegang oleh pemilik media. Dalam hal ini ketika tekanan datang untuk mendorong, pekerja secara individu dan rutinitas mereka harus tunduk pada organisasi yang lebih besar tujuanya. Shoemaker \& Reese dalam Mardhiyani (2015). Radar Sulbar merupakan anak perusahaan dari Fajar Group dan Jawa pos, secara hirarki posisi tertinggi dipegang oleh Komisaris Utama, Direktur Utama dan Direktur Pelaksana. Meski pucuk kekuasaan berada di tangan para direksi perusahaan induk, redaksi Radar Sulbar tetap diberikan keleluasaan dalam menentukan juga menyusun materi pemberitaan. Peran redaktur bisa menjadi penyeimbang kepentingan bisnis dan jurnalisme Abrar (2010).
Gatekeeping Level Extramedia. Instusi di luar media yang mempengaruhi proses gatekeeping Shomaker \& Vos dalam Mardhiyani (2015) diantaranya pasar, khalayak dan iklan. Radar Sulbar sebagai perusahaan media tidak hanya menggantungkan keuntungan di sektor pelanggan saja namun hidup dari iklan. Pengiklan akan melakukan berbagai hal termasuk memaksa media meng embargo berita yang buruk bagi mereka. Oleh sebab itu isi media secara langsung memiliki korelasi dengan kepentingan pihak yang menandai mereka. Shomaker dan Vos dalam Mardhiyani (2015). Kerjasama iklan advetorial di Radar Sulbar juga lebih banyak bersumber dari pemerintah baik itu provinsi dan kabupaten. Meski demikian beberapa kali Radar Sulbar berada di posisi yang cukup sulit, khususnya yang melibatkan klien yang beriklan.

Gatekeeping Level Ideologi. Ideologi dalam level sistem sosial ini tentu akan sangat berpengaruh terhadap isi atau program yang akan di sampaikan kepada masyarakat, terlebih jika level ini di kuasai kelompok dominan (pemilik media) informasi yang di produksi merepresentasikan fenomena yang melekat pada sumber informasinya yang kemungkinan merepresentasikan berbagai ideologi dari sumber informasi yang di produksi Mardhiyani (2015). Asumsi yang tertera diatas, pemilik media memiliki pengaruh terhadap isi pemberitaan, maka di Radar Sulbar pengaruh tersebut belum terlihat jelas. Pasalnya Radar Sulbar yang meski memiliki Chairman (Fajar Group) seorang H.M Alwi Hamu, yang juga merupakan tokoh pers senior di Sulsel dan juga masuk dalam lingkungan politik nasional, implikasi nya tidak sama dengan jaringan perusahaan media milik Surya Paloh atau Abu Rizal Bakrie yang sangat terbaca, menjadi salah satu penyokong kepentingan pemilik modal. Selain itu, karna Radar Sulbar merupakan anak perusahaan jawa pos ideologi secara umum tentu saja memiliki kesamaan. Salah satunya berdasarkan pancasila dan fungsi mencerdaskan bangsa. Namun sebagai koran dengan skala lokal, Radar Sulbar dalam misinya yang tertulis menyebutkan, peranya untuk mendorong percepatan pembangunan Sulbar termasuk percepatan perda RTRW. Dari seluruh temuan di atas peneliti melihat kebijakan redaksional Radar Sulbar baik itu berita pendidikan dan jenis lainya dipengaruhi 
oleh penjabaran diatas. Faktor yang lebih berperan adalah ideologi dan organisasi. Konteks ideologi Radar Sulbar sebagai harian umum melihat setiap jenis isu sama kedudukanya termasuk pendidikan yang menjadi tema penelitian. Perspektif Radar Sulbar, isu yang hangat saat ini bisa saja berganti di ke eskokan harinya, sehingga fokus pemberitaan cukup dinamis karna melihat kondisi yang berkembang saat itu.

Kelebihan : Radar Sulbar memiliki rubrik Go madrasah yang terbit setiap sabtu. Kebijakan tersebut jelas membuka ruang ekspose kepada sekolah berbasis agama sekaligus ingin meluruskan stigma yang telah lama mengakar bahwa pesantren merupakan sarana untuk mencetak generasi dengan faham radikalisme. Kelebihan lainya, konsistensi pemberitaan Radar Sulbar yang meski memiliki sejumlah kerjasama iklan dan advetorial dengan para stakeholder pendidikan (Dinas Pendididkan dll), tidak mengurangi ketajaman fungsi kontrol melalui berita yang di sajikan walau menyangkut kebijakan yang di anggap tidak berpihak kepada masyarakat. Radar Sulbar memegang prinsip - prinsip yang tertuang dalam sembilan elemen dasar jurnalistik yang dicetuskan oleh Bill Kovach. Pada butir ke dua disebutkan media massa harus loyal kepada masyarakat Setiati (2005).

Kelemahan : Pada rubrik Health and Education (HE) penulis menemukan kekurangan bahwa berita dalam rubrik tersebut lebih banyak mengulas berita pendidikan nasional yang di sadur dari JPNN dan hanya sebagai kecil berita lokal di Sulbar. Dalam hal ini media tidak boleh lepas dari konteks pemberitaan yang dikehandaki pembaca. Seperti yang ditegaskan pemegang saham Fajar Group yang juga merupakan komisaris utama HIC Syamsu Nur bahwa seharusnya media di daerah kembali ke konten lokal, dimana isi berita tidak lagi bergantung pada jakarta. Menurutnya mengangkat isu lokal jauh lebih penting karena lebih mendekatkan surat kabar dengan pembacanya fajar.co.id (2016). Dari perspektif berita, Stieler dan Lipmann dalam Kusumaningrat (2005) mengatakan peristiwa yang mengandung unsur kedekatan dengan pembaca, akan menarik perhatian. Majene masih merancang bentuk model pendidikan yang ideal sebagai pusat pendidikan di Sulawesi barat, media seharusnya membuka membuka ruang dengan menyediakan kolom di halaman Radar Sulbar. Hal tersebut selaras dengan sembilan elemen dasar dalam media massa yang di rumuskan Bill Kovach, yang salah satu poin nya (6) yakni media harus menyediakan forum publik untuk kritik maupun dukungan warga Setiati (2005).

\section{KESIMPULAN DAN SARAN}

Konsep harian umum yang dijalankan Radar Sulbar menjadi acuan Redaksi dalam menata pemberitaan. Kebijakan Redaksional Radar Subar yang mendukung Majene sebagai pusat pendidikan di Sulbar, dilakukan dengan memberi penguatan kepada beberapa isu pendidikan saja. Faktor - faktor yang mempengaruhi kebijakan redaksional Radar Sulbar terkait berita pendidikan diantaranya, faktor individu, rutinitas, organisasi, extra media dan ideologi. Dari seluruh temuan tersebut faktor yang lebih berperan diantaranya adalah ideologi dan organisasi. Kelebihan kebijakan redaksional Radar Sulbar dalam mendukung Majene sebagai pusat pendidikan di Sulbar terlihat dari beberapa rubrik pendidikan yang di hadirkan. Salah satunya Rubrik Go madrasah, dimana kebijakan tersebut seolah ingin meluruskan stigma bahwa pesantren merupakan sarana pencetak generasi faham radikalisme. Kelemahan : Rubrik Health and Education (HE) masih di dominasi berita nasional yang di sadur dari JPNN dan hanya sebagai kecil berita lokal di Sulbar. Kebijakan dalam mendukung Majene sebagai kota pendidikan, seharusnya dilakukan dengan memberikan porsi pemberitaan pendidikan lokal yang sepadan dengan predikat Majene sebagai pusat pendidikan di Sulbar. Radar Sulbar semestinya menekankan pemberitaan pendidikan dengan tidak hanya melihat dari sisi momentum saja, namun memunculkan isu pendidikan yang lebih banyak lagi. Baik itu terkait prestasi ataupun kritik atas ironi pendidikan di Majene. Radar Sulbar di harapkan memunculkan rubrik interaktif mengenai pendidikan di Sulbar, selain dimaksudkan menjaring ide terkait peningkatan kualitas pendidikan tapi juga menjadi corong klarifikasi.

\section{DAFTAR PUSTAKA}

Abrar N A. (2011). Analisis Pers Teori dan Praktik. Yogyakarta : Cahaya Atma Pustaka. 
Alwihamu. (2016). Bangun citra dan-SDM.

Diakses 17 Juli 2016. Avilable from:

htpp//www.radarselatan.fajar.co.id.

Kusumaningrat $\mathrm{H}$ \& Kusumaningrat, $\mathrm{P}$ (2005). Jurnalistik Teori dan Praktik, Bandung: Remaja Rosada Karya.

Mardhiyani N L. (2015). Kebijakan Redaksional Suara Merdeka Tentang Pemberitaan Kearifan Lokal Semarang di Edisi Lokal Semarang Metro. Universitas Dipenogoro Semarang.(2228)

Morrisan, M.A. et al. (2010). Teori Komunikasi Massa. Bogor: Ghalia Indonesia

Setiati E. (2005). Ragam Jurnalistik Baru dalam Pemberitaan, Yogyakarta: Andi Offset

Sumadirida H. (2005). Menulis Artikel dan Tajuk Rencana, Panduan Praktis Penulis dan Jurnalis Professional. Bandung : Simbiosis Rekatama Media.

Tamburaka A. (2012). Agenda Setting Media Massa. Jakarta: Rajagrafindo Persada.

Tebba S. (2005). Jurnalistik Baru. Ciputat : Kalam Indonesia

Tohir M. (2013). Kebijakan Redaksional Surat Kabar Republika dalam Menentukan Berita yang Dipilih Menjadi Headline. Universitas Islam Negri Syarif Hidayatullah Jakarta.( 3540 ) 